\title{
INFLUENCE OF POTASSIUM IONS ON CONTRACTION OF THE VAS DEFERENS ISOLATED FROM GUINEA-PIG
}

\author{
Jiro SUGIMOTO and Mitsuhiro NAGATA \\ Department of Pharmacology. Kansai Medical School, Moriguchi-City, Japan
}

Accepted May 17, 1973

\begin{abstract}
The role of potassium ions in the contraction of the vas deferens isolated from guinca-pig has been investigated herein. The preparation kept in an isotonic sucrose medium comprised of $0.07 \%$ sodium bicarbonate and $0.1 \%$ glucose was contracted by the addition of potassium ions at $5.6 \mathrm{mM}$, the concentration of which was the same as that in Locke's solution. When cakcium ions, at any concentration, were used in place of potassium ions, the contraction was undiscernable, and when the calcium ion concentration exceeded $1.7 \mathrm{mM}$ in the medium, the potassium induced contraction was depressed. This potassium induced contraction was not observable when the preparation had been pretreated by calcium-free Locke's solution, potassium-free Locke's solution, or strophanthin- $G$ in large amounts. This contraction was seen even in the preparation, which had hardly responded to nicotine applied repeatedly. From these results, it is presumed that: potassium ions are essential for the initiation of smooth muscle contraction in the vas deferens, calcium ions present in the medium inhibit this potassium action, and smooth muscle contraction of vas deferens requires at least the presences of calcium ions, potassium ions, and ATP-ase activity in the tissus.
\end{abstract}

Many investigators have attempted explanations concerning the contraction mechanism of smooth muscle (1-4), however much remains to be elucidated. In the present experiment, it was discovered that the vas deferens, isolated from guinea-pigs and kept in an isotonic sucrose medium, could be contracted with the addition of only $5.6 \mathrm{mM}$ of potassium chloride to the medium in which the sodium bicarbonate and the glucose concentrations were only $0.07 \%$ and $0.1 \%$, respectively. On the other hand, calcium ions ellicited hardly any response; on the contrary, they suppressed the muscular contraction induced by the potassium ions. This evidence suggests that the potassium ions in the medium are essential to the initiation of smooth muscle cuntraction. Experiments were thus performed towards further clarification of this contraction mechanism.

\section{MATERIALS AND METHODS}

Male adult guinea-pigs weighing 350 10 $450 \mathrm{~g}$ were used. After sacrifice, the vas deferens was excised. A muscle preparation was then suspended in a Magnus' apparatus in a Locke's solution saturated with pure oxygen at 30 to $31^{\circ} \mathrm{C}$. Thereupon, the preparation was loaded with approx. $0.1 \mathrm{~g}$ of tension, and the contractions induced by drugs or inorganic ions were recorded on a smoked drum by means of the lever.

The Locke's solution used as a standard solution consisted of $\mathrm{NaCl} 9.0 \mathrm{~g}(154 \mathrm{mM})$, 
$\mathrm{KCl} 0.42 \mathrm{~g}(5.6 \mathrm{mM}), \mathrm{CaCl}_{2} 0.24 \mathrm{~g}(2.2 \mathrm{mM}), \mathrm{NaHCO}_{3} 0.7 \mathrm{~g}(8.3 \mathrm{mM})$, and glucose $1.0 \mathrm{~g}$ $(5.5 \mathrm{mM})$ per litre of distilled water. Constituents of a sucrose medium and modified Locke's solutions which played leading roles herein are summarized in Table 1. The drugs used were nicoline (Merck) and strophanthin-G (Uabanin, Takeda).

This work was done in the early spring season.

TABLE 1. Compositions of media used in this experiment.

\begin{tabular}{|c|c|c|c|c|c|c|}
\hline \multirow{2}{*}{ Abbrev. of media } & \multicolumn{2}{|c|}{ Constituents } & \multicolumn{4}{|c|}{ g) except for water in one litre of medium } \\
\hline & $\mathrm{NaCl}$ & $\mathrm{KCl}$ & $\mathrm{CaCl}_{2}$ & $\mathrm{NaHCO}_{3}$ & Glucose & Sucrose \\
\hline Locke's solution & 9.0 & 0.42 & 0.24 & 0.7 & 1.0 & - \\
\hline Ca-free Locke's solution & 9.2 & 0.42 & - & 0.7 & 1.0 & - \\
\hline K-free Locke's solution & 9.3 & - & 0.24 & 0.7 & 1.0 & - \\
\hline Sucrose medium & - & - & - & 0.7 & 1.0 & 111.5 \\
\hline
\end{tabular}

\section{RESULTS}

1) Vas deferens contraction induced by a small amount of potassium ions when the preparation was maintained in an isotonic sucrose medium

When a vas deferens preparation was kept in an isotonic sucrose medium containing $0.07 \%$ sodium bicarbonate and $0.1 \%$ glucose for $5-180$ min, contraction at tension levels from 0.3 to $0.5 \mathrm{gw}$ took place soon after the addition of $5.6 \mathrm{mM}$ of potassium chloride (Fig. 1). The concentration of potassium ions used in this experiment was the same as that contained in a Locke's solution. This contraction was seldom observed in a medium containing sodium ions at $20 \%$ or more of those contained in a Locke's solution.

Thus, since the sodium ions were few and the calcium ions were free in this medium, the contraction described maty be regarded as the result of potassium ions acting on the vas deferens in the environment.

Morcover, this contraction was seen even in the preparation, which had been longitudinally cut on one side and of which the inner surface had had contact with the medium.

2) Influence of added calcium ions on the vas deferens maintained in a sucrose medium

When potassium chloride was replaced by calcium chloride, very little change in muscular tension was observed, however, the contraction induced by the potassium ions was depressed when the calcium ions in the sucrose medium exceeded $1.7 \mathrm{mM}$. Figs. 1 and 2 show the suppressive effects of calcium ions on potassium induced contraction, when the calcium ions were added at a concentration of $1 / 1(2.2 \mathrm{mM}), 3 / 4(1.7 \mathrm{mM}), 5 / 8(1.4$ $\mathrm{mM}), 1 / 2(1.1 \mathrm{mM})$, or $0 / 1$ of that of the Locke's solution $10 \mathrm{~min}$ before the $5.6 \mathrm{mM}$ addition of potassium ions to the sucrose medium.

Potassium contraction being suppressed by the presence of calcium ion, the latter proved to be hardly essential and even to be depressant to a potassium induced contraction of vas deferens in a sucrose medium. 


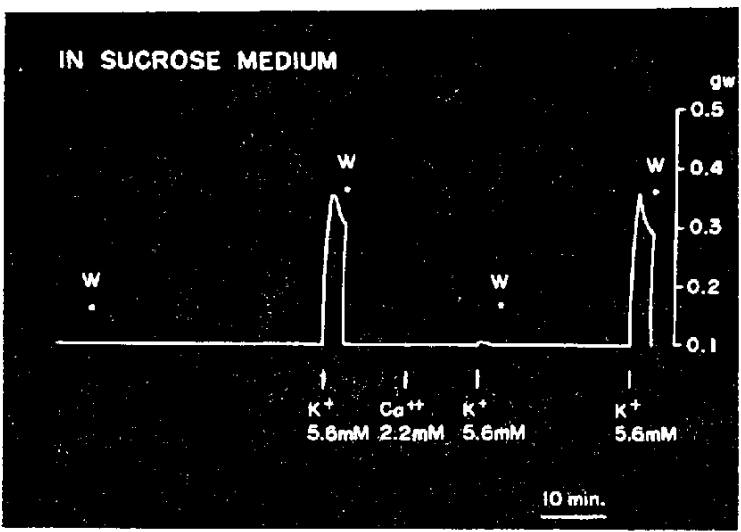

FIG. 1. Contraction of the vas deferens isolated from guinea-pig: when kept in an isotonic sucrose medium consisting of $0.07 \% \mathrm{NaHCO}_{3}$ and $0.1 \%$ glucose, the addition of $\mathrm{KCl}$ at $5.6 \mathrm{mM}$ induced contraction. $\mathrm{CaCl}_{2}$ at $2.2 \mathrm{mM}$ did not do so and inhibited the $\mathrm{KCl}$ induced contraction. At (W) the bath fluid was changed for a sucrose medium at which time the drum was stopped for $20 \mathrm{~min}$.

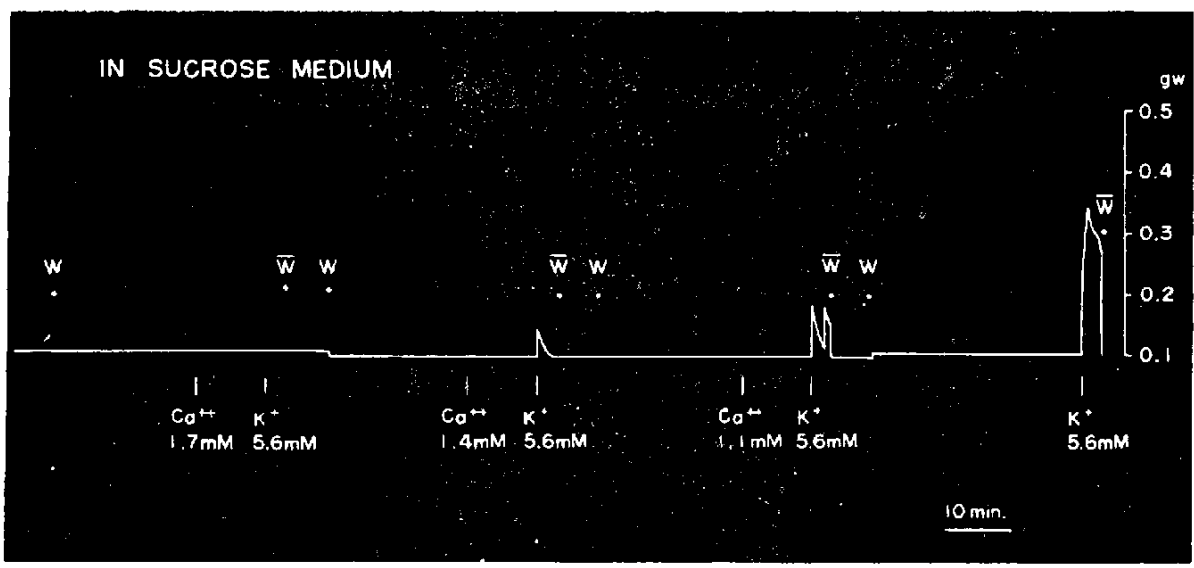

FIG. 2. Contraction of the vas deferens isolated from guinea-pig: when kept in an isotonic sucrose medium consisting of $0.07 \% \mathrm{NaHCO}_{3}$ and $0.1 \%$ glucose, the contraction induced by $\mathrm{KCl}$ at $5.6 \mathrm{mM}$ was influenced by the presence of $\mathrm{CaCl}_{2}$ added at several concentrations. At $(W)$ or $(\bar{W})$, the bath fluid was changed for a sucrose medium or the Locke's solution, respectively, at which time the drum was stopped for $20 \mathrm{~min}$.

3) Conditions preventing the vas deferens contraction induced by a small amount of potassium ions in a sucrose medium

When the preparation had been in a calcium-free Locke's solution for one hr before transfer to a sucrose medium, the following addition of potassium ions at $5.6 \mathrm{mM}$ seldom induced a contraction.

When the preparation had been in a potassium-free Locke's solution for three hr before transfer to a sucrose medium, the following addition of potassium ions at $5.6 \mathrm{mM}$ seldom induced a contraction. 
When the preparation had been in the sucrose medium containing strophanthin-G $8 \times 10^{-2} \mathrm{mM}$ for one $\mathrm{hr}$, the addition of potassium ions at $5.6 \mathrm{mM}$ seldom induced a contraction.

4) Influence of nicotine on the vas deferens contraction induced by a small amount of potassium ions in a sucrose medium

In a sucrose medium as well as in a Locke's solution, the addition of nicotine at $5 \times$ $10^{-2}$ or $5 \times 10^{-3} \mathrm{mM}$ induced the supramaximal or near to minimal contraction respectively in the preparation. The effect of nicotine $5 \times 10^{-2} \mathrm{mM}$ on the preparation disappeared in a sucrose medium, when the preparation had been pretreated two or three times with nicotine $5 \times 10^{-3} \mathrm{mM}$ in the medium. In this preparation, already unresponsive to the supramaximal dose of nicotine, the addition of potassium ions at $5.6 \mathrm{mM}$ did induce a contraction.

\section{DISCUSSION}

As the vas deferens contracted with the addition of potassium ions at an amount as low as $5.6 \mathrm{mM}$ to the sucrose medium, potassium ions can be well regarded as the one substance essential to the initiation of this contraction; in other words, at least calcium ion in the medium is not required in this process. Furthermore, since this induction was seen even in the preparation which had been unresponsive to nicotine after repeated applications, this action of potassium ions cannot be attributed to ganglionic stimulation.

As described in experiment 3, when the preparation had been pretreated in a calcium-free Locke's solution, the potassium induced contraction of the preparation failed to occur in the sucrose medium, which was also true when the preparation had been pretreated in a potassium-free Locke's solution. As it has been reported that the calcium or potassium ions in a prepared tissue are reduced in a calcium-free or potassium-free Locke's solution $(5,6)$ respectively, it appears that the calcium ions and potassium ions already present in the tissue may have some relation to the contraction induced by added potassium ions in the sucrose medium. Assuming that ATP-ase activity in the tissue is reduced by the action of a large amount of cardiac glycoside (7), the failure of potassium to induce contraction may be ascribed to the reduction of ATP-ase activity in the tissue resulting from this pretreatment.

Therefore, it can be assumed that for the contraction of the vas deferens in a sucrose medium, the environmental requirement is the presence of potassium ions, and the tissue requirement is the presence of calcium ions, potassium jons, ATP-ase activity, and other as yet unknown factors. Since the contraction of the vas deferens induced by potassium ions in a sucrose medium is of only short duration, there is some possibility that this phenomenon presents only the initial contraction process of a smooth muscle maintained in a normal environment.

The changes of action potential induced by inorganic ions in the smooth muscle kept in a sucrose medium and the effects of several drugs on the muscle will be reported in succeeding papers. 


\section{REFERENCES}

1) Fatt, P. ANd Ginsborc, B.L.: J. Physiol. 142, 516 (1958)

2) Hagiwara, S, and Naka, K.: J. gen. Physiol. 48, 141 (1964)

3) Nonomura, Y., Hotta, Y. and Ohashi, H.: Science 152, 97 (1966)

4) Bauer, H., Goodford, P.J. ANd Hilter, J.: J. Physiol. 176, 163 (1965)

5) Sugimoto, J. anis Nash, C.W.: Proc. 11 th Ann. Meet. Canad. Fed. Biol. Socs 324 (1968)

6) Nagata, M., Sugimoto, J. and Fugono, R.: Japan. Circul. J. 36, 935 (1972)

7) Palmer, R.F., Lassfitr, K.C. and Mlivin, S.: Archs. Biochem. Biophys. 113, 629 (1966) 